\title{
Simultaneous measurement of the maximum oscillation amplitude and the transient decay time constant of the QCM reveals stiffness changes of the adlayer
}

Received: 10 March 2003 / Revised: 1 May 2003 / Accepted: 20 May 2003 / Published online: 9 July 2003

(C) Springer-Verlag 2003

\begin{abstract}
Interpretation of adsorption kinetics measured with a quartz crystal microbalance (QCM) can be difficult for adlayers undergoing modification of their mechanical properties. We have studied the behavior of the oscillation amplitude, $A_{0}$, and the decay time constant, $\tau$, of quartz during adsorption of proteins and cells, by use of a homemade QCM. We are able to measure simultaneously the frequency, $f$, the dissipation factor, $D$, the maximum amplitude, $A_{0}$, and the transient decay time constant, $\tau$, every $300 \mathrm{~ms}$ in liquid, gaseous, or vacuum environments. This analysis enables adsorption and modification of liquid/ mass properties to be distinguished. Moreover the surface coverage and the stiffness of the adlayer can be estimated. These improvements promise to increase the appeal of QCM methodology for any applications measuring intimate contact of a dynamic material with a solid surface.
\end{abstract}

Keywords QCM · Amplitude · Viscoelasticity · Decay time constant $\cdot$ Protein $\cdot$ Cell

\section{Introduction}

The quartz crystal microbalance (QCM) is an ultrasensitive technique, which allows us to follow in real time the adsorption kinetics of molecules, proteins, and cells onto

C. G. Marxer ( $($ M $)$. M. C. Coen - L. Schlapbach

Solid State Physics Research Group, University of Fribourg, Pérolles, 1700 Fribourg, Switzerland

e-mail: Carine.Galli@unifr.ch

H. Bissig.

Soft Condensed Matter Physics Group, University of Fribourg,

Pérolles, 1700 Fribourg, Switzerland

U. F. Greber

Institute of Zoology, University of Zürich,

Winterthurerstrasse 190, 8057 Zürich, Switzerland

L. Schlapbach

Swiss Federal Laboratories for Material Testing and Research, Ueberlandstr. 129, 8600 Dübendorf, Switzerland a surface [1]. Its sensor consists of a thin quartz crystal (generally AT-cut) sandwiched between two evaporated metal electrodes [2]. Application of an alternating voltage with a frequency similar to the quartz resonance frequency induces oscillation of the quartz. The first measurements were performed by Jones et al. and Meiure et al. under vacuum for deposition of metals [3, 4]. In this case the Sauerbrey relation [5] predicts a linear relation between the adsorbed mass and the measured resonance frequency shift:

$\Delta f=-\frac{2 f_{0}^{2}}{\sqrt{\mu_{q} \rho_{q}}} \frac{\Delta m}{A}=-\frac{2 f_{0}^{2}}{v_{q} \rho_{q}} \frac{\Delta m}{A}=-\frac{1}{C} \cdot \Delta m$

where $\Delta f$ is the measured frequency shift, $f_{0}$ the resonance frequency, $\Delta m$ the adsorbed mass, and $C$ the quartz sensitivity constant, which depends on the intrinsic properties of the quartz crystal only $\left(v_{\mathrm{q}}=3340 \mathrm{~m} \mathrm{~s}^{-1}\right.$, the velocity of the acoustic shear waves perpendicular to the quartz surface, $\mu_{\mathrm{q}}=2.947 \times 10^{11} \mathrm{~g} \mathrm{~cm}^{-1} \mathrm{~s}^{-2}$, the shear modulus of quartz, $\rho_{\mathrm{q}}=2.648 \mathrm{~g} \mathrm{~cm}^{-3}$, the density of quartz, and $A$ is the area of the electrodes). This equation is valid under the following assumptions:

1. the adsorbed mass is perfectly bound to the electrode and does not slip on the surface;

2. it is elastic, i.e. it does not undergo viscoelastic deformations;

3. the mass is forming an uniform layer; and

4. the material acoustic impedance is identical with that of the quartz.

Since Nomura [6] showed that the QCM can operate not only in vacuum and air but also under liquid, interest in the QCM increased greatly due to potential applications in electrochemistry, immunology, biotechnology, and cell biology. However, measurements in a liquid environment are much more complex than under vacuum and the Sauerbrey equation is not valid. It has been shown that for large molecules, for example proteins, the adsorbed mass calculated with the Sauerbrey equation is systematically overestimated [7], because water molecules trapped between the adsorbed proteins vibrate simultaneously with 
the protein adlayer, adding to the measured mass. Moreover changes in the mass and liquid properties (density, viscosity) also influence the measured resonance frequency $[8,9]$.

It is therefore essential to measure simultaneously all possible parameter(s) and not only the frequency. Various groups have developed methods to measure the dissipation factor $D=D(f, \tau)[10]$ or $Q$-factor $Q=1 / D[11]$ in addition to $f$. Nevertheless, this technique alone does not enable determination of whether the frequency shift is due to an adsorbed mass or is a result of modifications of the liquid/mass properties, because $f$ is contained in $D$ [12]. It has been shown that the interpretation of QCM data is enhanced by using steady-state techniques, i.e. by measuring the resistance in addition to the resonance frequency $[13,14,15,16,17,18]$.

Using different agents, such as water-ethanol mixtures, proteins, and cells we determined the additional information given by the maximal oscillation amplitude and the decay time constant in the case of a transient technique. This allowed us to obtain information about energy losses, to separate the contributions of liquid and adsorbed mass to the measured frequency, and to detect modifications in the stiffness of the adlayer. Interpretation of the QCM data is therefore improved, especially concerning the adsorption of viscoelastic mass.

\section{Materials and methods}

Proteins

Two proteins different in size and shape have been used for this study, protein A and fibronectin. Protein A (Staphylococcus aureus, Fluka, Buchs, Switzerland) is a globular protein of $44.2 \mathrm{kDa}$. Its average diameter is $3 \mathrm{~nm}$ [19] and the isoelectrical point is $\mathrm{p} I=$ 5.1 [20]. The concentration was $1.6 \mu \mathrm{mol} \mathrm{L}^{-1}$ and it was diluted in nanodeionized water kept in air. The resulting $\mathrm{pH}$ was between 5 and 6.

Fibronectin (Sigma, Buchs, Switzerland) is a large multidomain glycoprotein, which is almost $130 \mathrm{~nm}$ long [21]. Studies of the hydrodynamic properties of fibronectin in solution suggested a flexible conformation [22]. The stock solution was $1.1 \mathrm{mg} \mathrm{mL}^{-1}$ in $0.05 \mathrm{~mol} \mathrm{~L}^{-1}$ Tris-buffered saline solution at a $\mathrm{pH}=7.5$ and we diluted it to a final concentration of $0.55 \mathrm{mg} \mathrm{mL}^{-1}$.

\section{Cells}

TC7 African green monkey kidney epithelial cells were grown on plastic dishes in a humidified $5 \% \mathrm{CO}_{2}$ air atmosphere at $37^{\circ} \mathrm{C}$ in DMEM (Gibco) containing 10\% FBS (Hyclone) and $2 \mathrm{mmol} \mathrm{L}^{-1}$ glutamine, as described earlier [23]. Near confluent cells were detached from the substratum by short trypsinisation $\left(0.5 \mathrm{mg} \mathrm{nL}^{-1}\right)$ at $37^{\circ} \mathrm{C}$ and immediately resuspended in RPMI medium (Gibco) supplemented with $20 \mathrm{mmol} \mathrm{L}^{-1}$ Hepes- $\mathrm{NaOH}(\mathrm{pH}=7.4), 10 \%$ FBS, 2 mmol L ${ }^{-1}$ glutamine, $1 \%$ non-essential amino acids and $100 \mathrm{U} \mathrm{mL}^{-1}$ penicillin $/ 0.1 \mathrm{mg} \mathrm{mL}^{-1}$ streptomycin. Cells were immediately transferred to the QCM at a concentration of $10.2 \times 10^{4}$ cells $\mathrm{mL}^{-1}$.

THP1 acute monocytic leukeınia cells were maintained in suspension as described in Ref. [24]. $31 \times 10^{4}$ cells $\mathrm{mL}^{-1}$ were collected by centrifugation and resuspended in Iscove's medium (Life Technologies) supplemented with $10 \% \mathrm{FBS}, 2 \mathrm{mmol} \mathrm{L}^{-1}$ glutamine and $100 \mathrm{U} \mathrm{mL}^{-1}$ penicillin. $0.1 \mathrm{mg} \mathrm{mL}^{-1}$ streptomycin and transferred to the QCM.

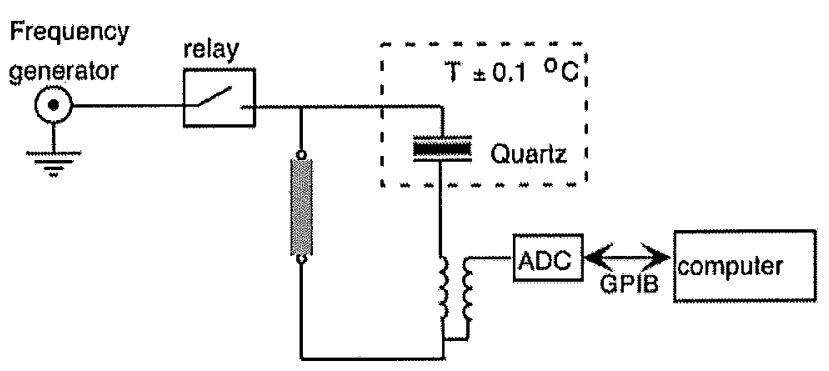

Fig. 1 Experimental set-up of our home-made QCM

The quartz crystal microbalance (QCM)

The quartz crystal microbalance used for this study is a homemade microbalance which can measure simultaneously the series resonance frequency, $f$, the dissipation factor, $D$, the maximal oscillation amplitude, $A_{0}$, of the quartz and the transient decay time constant $\tau$. The experimental set-up shown in Fig. 1 is used for experiments in liquid environments, but it can also be employed in air or under vacuum.

When the relay is closed, a frequency generator (Agilent $33120 \mathrm{~A}$ ) excites the quartz crystal at its resonance frequency, which is constantly adjusted during the experiment. The drive voltage supplied by the signal generator is kept constant. After almost $3 \mathrm{~ms}$ the relay is opened and the quartz amplitude decays as an exponentially damped sinusoidal $[10,25]$ :

$A(t)=A_{0} e^{\frac{-t}{r}} \sin (\omega t+\phi), t \geq 0$

where $\tau$ is the transient decay time constant, and $\phi$ the phase. The decay curve is recorded with a sampling frequency, $f_{\mathrm{s}}$, of a second frequency generator (Stanford DS345), so that due to aliasing the measured frequency $f_{\mathrm{m}}$ is:

$f_{m}=f_{s} \cdot f r a c\left(\frac{f}{f_{s}}\right)$

where $f_{\mathrm{m}}$ is lower than the oscillation frequency $f$ of the quartz crystal. Nevertheless, the frequency shifts $\Delta f$ and $\Delta f_{\mathrm{m}}$ are similar, allowing us to detect the true frequency shifts during adsorption. The amplitude is digitized and stored in the analog-to-digital converter (ADC), and the values are then transmitted to the computer via the GPIB interface. While this measurement is fitted to obtain the different parameters, the relay is already closed for the next measurement. A program developed in LabView (National Instruments) acquires, treats, and shows the data over hours. The resolutions obtained for $3 \mathrm{~Hz}$ measurement rate are $f \pm 2 \mathrm{~Hz}, D \pm 0.5 \times 10^{-6}$, $A_{0} \pm 50$ a.u. and $\tau \pm 1.4 \times 10^{-6} \mathrm{~s}$ for $10 \mathrm{MHz}$ quartz crystals operating into deionized water at $25 \pm 0.1^{\circ} \mathrm{C}$. Under vacuum the resolution is much better with $f \pm 0.03 \mathrm{~Hz}, D \pm 0.5 \times 10^{-7}, A_{0} \pm 3$ a.u., and $\tau \pm 1.5 \times$ $10^{-8} \mathrm{~s}$. Using the Sauerbrey relation this corresponds to changes in mass of $m \pm 9 \mathrm{ng} \mathrm{cm}^{-2}$ in liquid and $m \pm 0.135 \mathrm{ng} \mathrm{cm}^{-2}$ under vacuum.

The quartz crystal and the solutions are placed in a temperature-control box at $T \pm 0.1^{\circ} \mathrm{C}$. Therefore the temperature remains constant during the whole experiment and during the solution exchanges, avoiding frequency shift duc to changes in the density and the viscosity of the liquid and due to modification of the quartz. sensitivity. The quartz is sandwiched between two Plexiglas pieces sealed with Viton O-rings, where liquid exchanges are possible through a tubing system. Only one side of the crystal is in contact with $80 \mu \mathrm{L}$ of licuid. This experimental set-up ensures that no evaporation of liquid occurs during the measurements.

All experiments were performed with quartz having smooth $\mathrm{Au}$ electrodes (Internal Crystal Manufacturing, OK, USA). The side of the crystal in contact with the liquid has a larger electrode area, so that the conductivity and dielectric constant of the liquid does not disturb the measurements [26].

Before each protein experiment, the system was equilibrated with deionized water at a temperature of $25 \pm 0.1^{\circ} \mathrm{C}$. The cell ex- 
periment was performed at $37 \pm 0.1^{\circ} \mathrm{C}$ and the system was preequilibrated with growth media lacking cells.

\section{Theory and results}

Equivalent circuit and physical properties

An AT-cut quartz crystal can be described by an electrical equivalent circuit, as shown in Fig. 2. It is composed of the series branch or motional branch in parallel with a capacitance $C_{0}$, which is the static capacitance of the quartz resonator with the electrodes. The motional branch defines the electromechanical characteristics of the quartz resonator with inertial component $L_{1}$, compliance of the quartz $C_{1}$, and energy dissipation during oscillation $R_{1}$. This model can also be converted to a mechanical model in which the mass is related to $L_{1}$, the energy stored during oscillation to $C_{1}$ and the energy losses to $R_{1}$ [27]. All these components are also related to the measured QCM parameters. Upon liquid loading the series resonance frequency is given by [28]:

$f=\frac{1}{2 \pi \sqrt{L_{1} C_{1}}}\left(1+\frac{C_{0} D^{2}}{2 C_{1}}\right)$

where $D=R_{1} / \omega L_{1}$. Kanazawa [9] found the following relation for the frequency shift under liquid without adsorbed mass compared to vacuum:

$\Delta f=-f_{0}^{3 / 2} \sqrt{\frac{\rho_{l} \eta_{l}}{\pi \mu_{q} \rho_{q}}}$

where $f_{0}$ is the resonance frequency, $\rho_{1}$ and $\eta_{1}$ are the density and viscosity of the liquid, and $\rho_{\mathrm{q}}$ and $\mu_{\mathrm{q}}$ are the density and the shear modulus of the quartz crystal, respectively. In the equivalent circuit this correction to the Sauerbrey equation would be represented by addition of a resistance $R_{1}$ and an inductance $L_{1}$ in the motional branch. This equation shows that the measured frequency is not only sensitive to mass changes (Sauerbrey), but also to changes in liquid properties. Similarly, changes in viscosity and density of adsorbed mass will induce additional frequency shifts. It has also been shown that the frequency sensitivity in terms of frequency change per mass density increases with increasing deposition for soft films [29].

The dissipation factor measures the dissipated energy over the stored energy and is given by:

$D=\frac{R_{1}}{2 \pi f L_{1}}=\frac{2}{\omega \tau}$

Changes of $R_{1}, L_{1}$ or $C_{1}$ will induce changes of $D$, and it is therefore difficult to determine which physical properties

Fig. 2 Equivalent circuit to a quartz crystal. $R_{1}, L_{1}$, and $C_{1}$ represent the total resistance, inductance and capacitance. Under mass and liquid loading, these values are modified in comparison with values in a vacuum

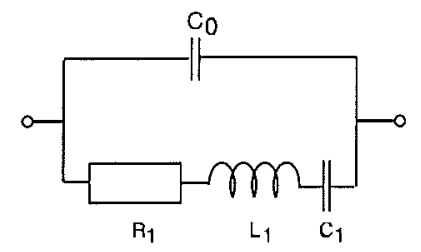

(adsorbed mass, energy stored, energy losses, density, viscosity) have induced the $D$ variation.

The use of additional parameter(s) is required to improve the interpretation of QCM data, especially for viscoelastic systems. With this in view the maximal oscillation amplitude $A_{0}$ of the voltage across the quartz crystal, which is proportional to the mechanical vibration amplitude of the quartz crystal, can be easily used in the case of a transient technique. Indeed it has been shown that when the parallel capacitance is eliminated, as in our system, a change in the voltage is proportional to the change in the motional resistance $[30,31,32]$. Furthermore a modification of the vibration amplitude of the quartz crystal is proportional to the change of the motional resistance [33].

Experiments performed under vacuum have shown that the maximal oscillation amplitude of a vibrating quartz crystal is linearly proportional to the quartz quality factor $Q=1 / D$ for a given applied voltage [34], confirming the theory developed for a bare quartz crystal [29]. The same behavior is observed for quartz in contact with different liquids, where no mass adsorption occurs. Figure 3 presents the maximal oscillation amplitude as a function of the dissipation factor for mixtures of water and ethanol at different relative concentrations. The maximal amplitude decreases linearly (water-ethanol curve) with an increase of the dissipation factor, $D$. An increase of the product of the liquid density $\rho_{1}$ and viscosity $\eta_{1}$ results in an increase of dissipated energy and therefore a decrease of amplitude, which is proportional to $\left(\rho_{1} \eta_{1}\right)^{1 / 2}$ (Fig. 4). The measurement is in accordance with different models [35, 36] and similar results have been obtained using steady state techniques [37]. Nevertheless, the proportionality between $A_{0}$ and $D$ is no longer valid when biological material is adsorbed. $A_{0}$ decreases continuously during protein A adsorption, in contrast to $D$, which presents a saturation value (inset in Fig. 3). During the adsorption of cells, which form

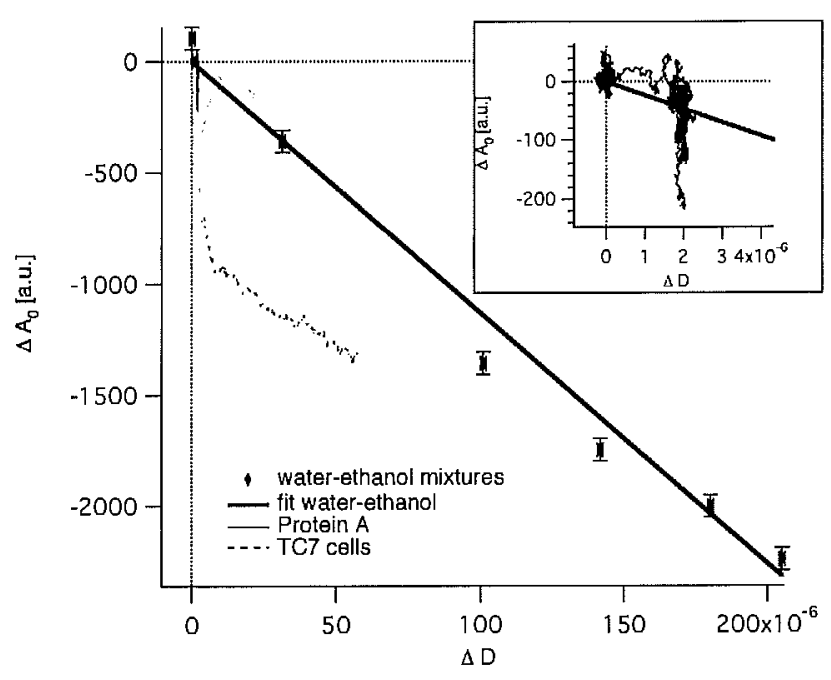

Fig. 3 Maximal oscillation amplitude $A_{0}$ as a function of dissipation factor $D$ for adsorption of water-ethanol mixtures, protein A, and TC7 cell. Inset: magnification of protein A curve 


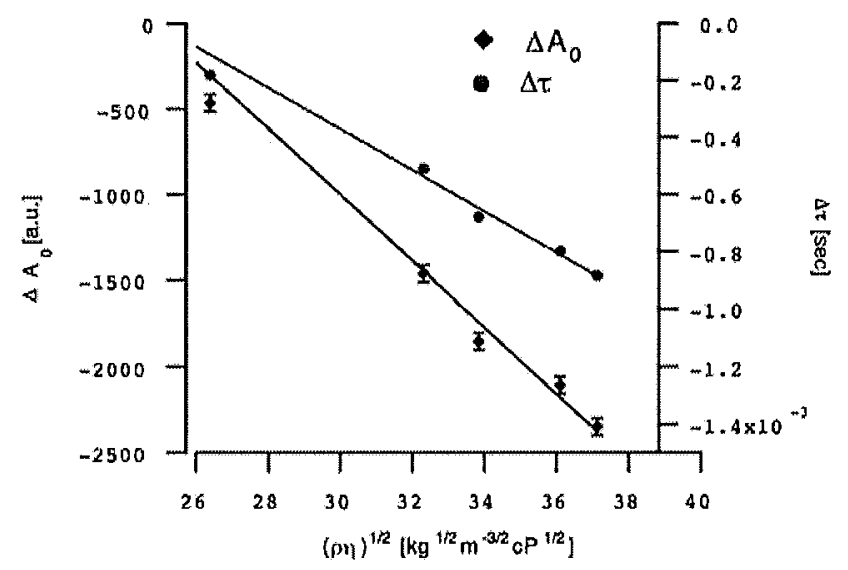

Fig. 4 The maximal amplitude and the transient decay time constant are proportional to liquid properties such as the density and the viscosity

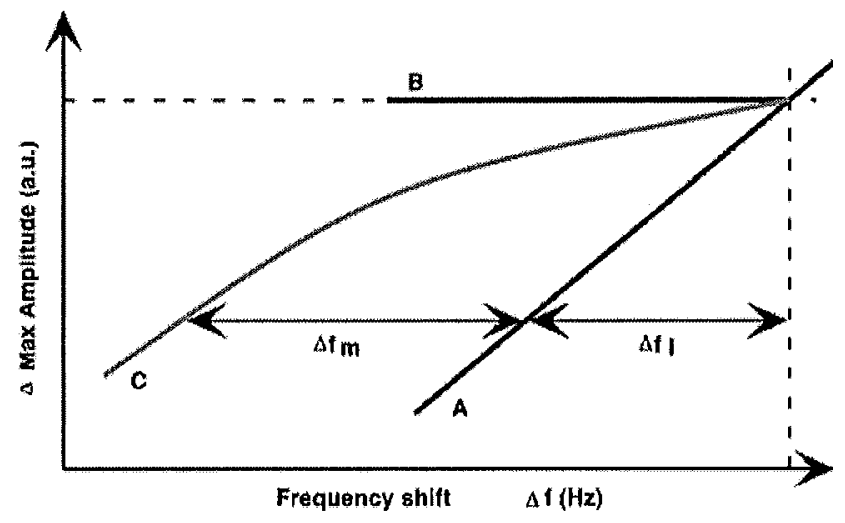

Fig. 5 Measuring the amplitude allows us to distinguish the contribution in frequency shift of liquid loading $\Delta f_{1}$ to adsorbed mass $\Delta f_{\mathrm{m}}$. (A) water-ethanol mixtures, $(B)$ rigid adsorbed mass, $(C)$ rigid adsorbed mass with changes in liquid properties

a viscoelastic system, $A_{0}$ and $D$ decrease, increase and then continue to decrease. Therefore additional information about viscoelastic properties of adlayer may be contained in the measured maximal amplitude $A_{0}$. The theoretical expression of $A_{0}$ is difficult to estimate and has not yet been exactly determined, since it contains all mechanisms of energy dissipation. For thin films in contact with the quartz, energy dissipation can arise from changes of the storage modulus $\left(G^{\prime}\right)$ or shear modulus $(\mu)$, loss modulus $\left(G^{\prime \prime}\right)$ or viscosity $(\eta)$ and/or thickness of the adlayer [38]. For a constant loss tangent $\alpha=G^{\prime \prime} / G^{\prime}$, the dissipated energy increases with increasing thickness of the adlayer $[39,40,41,42]$, except for some thicknesses at which film resonance appears. For most adlayer thickness the dissipated energy increases as $\alpha$ increases [42]. Moreover if the adsorbed mass slips on the surface or with increasing surface roughness, changes in the motional resistance can also occur.

Figure 5 shows the amplitude as a function of the frequency shift for different systems. The curve A represents the line obtained with modification of the liquid density and/or viscosity only (water-ethanol mixtures), where the amplitude decrease is linearly proportional to the frequency decrease. With pure mass (rigid) adsorption and no energy losses, curve B would arise, where the frequency decreases but the amplitude remains constant.

Finally the curve $\mathrm{C}$ corresponds to the adsorption of a rigid mass, where the solution viscosity and/or density are higher in comparison with the liquid present before the adsorption. The frequency decreases according to the Sauerbrey relation, due to the adsorbed mass, but it also decreases due to changes in the liquid properties according to Kanazawa's relation [9]. By modification of the mechanical properties of the adsorbed mass during adsorption, an additional frequency shift would occur. If curve $A$ is known, it is possible to distinguish between the contribution of the mass adsorption $\Delta f_{\mathrm{m}}$ and the contribution of the modification of the liquid properties $\Delta f_{l}$.

The last parameter we can measure is $\tau$, which enables calculation of the dissipation factor. Figure 4 shows that under liquid loading, $\tau$ is linearly proportional to the product of liquid density and viscosity, similarly to $f, D$, and $A_{0}$. $\tau$ decreases as the product of liquid density and viscosity increases. Moreover with adsorption of soft mass or if the adsorbed mass becomes softer, $\tau$ decreases according to:

$\tau=\frac{2 L_{1}}{R_{1}}$

where $\tau$ therefore represents the mass over the energy losses.

In summary the different measured parameters and their relationship to the physical properties of liquid and adlayer are listed in Table 1 . The storage modulus $G^{\prime}$ and the loss modulus $G^{\prime \prime}$ can be related to the shear elastic modulus, $\mu$, and the viscosity, $\eta$. Under liquid and mass loading, $\Delta f$ can be due to an increase of adsorbed mass and/or changes in the mechanical properties of the liquid and of the mass; $\Delta A_{0}$ is proportional to energy losses due to changes of liquid and/or mass properties; $\Delta \tau$ represents the changes of decay time due to different stiffness of the adlayer and/or of the liquid; and finally $\Delta D$ occurs due to adsorbed mass and/or viscoelastic changes of the adlayer and/or liquid.

Table 1 Relationship between the measured parameters and the components of the equivalent circuit, and their dependencies on physical properties, where the indices $\mathrm{m}$ and 1 correspond to the adsorbed mass and to the liquid, respectively. $m$ is the adsorbed mass, $\rho$ the density, $\eta$ the viscosity and $\mu$ the shear elastic modulus

\begin{tabular}{|c|c|c|}
\hline $\begin{array}{l}\text { Measured } \\
\text { parameter }\end{array}$ & $\begin{array}{l}\text { Equivalent } \\
\text { circuit }\end{array}$ & $\begin{array}{l}\text { Physical properties of liquid } \\
\text { and adlayer }\end{array}$ \\
\hline$\Delta f$ & $\approx-\Delta\left(\frac{1}{\sqrt{L_{1} C_{1}}}\right)$ & thickness $s_{\mathrm{m}}, \rho_{\mathrm{l}, \mathrm{m}}, \eta_{\mathrm{m}, 1}$ \\
\hline$\Delta A_{0}$ & $\approx-\Delta R_{1}$ & thickness $_{\mathrm{m}}, \rho_{\mathrm{ml}, \mathrm{l}}, \eta_{\mathrm{m}, l}, \mu_{\mathrm{m}, \mathrm{l}}\left(E_{\mathrm{loss}}\right)$ \\
\hline$\Delta \tau$ & $\approx \Delta\left(\frac{L_{1}}{R_{i}}\right)$ & thickness $_{\mathrm{m}}, \rho_{\mathrm{ml}, \mathrm{l}}, \eta_{\mathrm{m}, \mathrm{l}}, \mu_{\mathrm{m}, 1}\left(\operatorname{mass} / E_{\mathrm{loss}}\right)$ \\
\hline$\Delta D$ & $\approx \Delta\left(\frac{R_{1}}{f L_{1}}\right)$ & thickness $s_{\mathrm{m}}, \rho_{\mathrm{ml}, 1}, \eta_{\mathrm{m}, 1}, \mu_{\mathrm{m}, \mathrm{l}}$ \\
\hline
\end{tabular}




\section{Protein and cell adsorption}

The adsorption of proteins induces a decrease of frequency, as it can be seen in Fig. 6. The behavior is similar for cells after $16 \mathrm{~min}$. It may therefore correspond to adsorption of mass. Nevertheless, modification of the adlayer viscoelastic properties can influence the measured frequency shift, so that we have to consider the other measured parameters.

Figure 7 shows the amplitude shift, $\Delta A_{0}$, as a function of the frequency shift, $\Delta f$, for water-ethanol mixtures, protein and cell systems. $A_{0}$ reached approximately 6300 a.u. when the quartz crystal is immersed in water. First of all it can be seen that the progressive exchange of water with ethanol induces a decrease of $A_{0}$ linearly proportional to the decrease in frequency, because both parameters are linearly proportional to the product of liquid density and viscosity (Fig. 4).

In contrast to water-ethanol exchanges, the adsorption of protein $\mathrm{A}$ shows different kinetics. The protein $\mathrm{A}$ has been diluted in water and rheological measurements have shown that no viscosity changes occur in comparison with pure water $\left(\eta=1 \pm 0.01 \mathrm{mPas}\right.$ at $\left.25^{\circ} \mathrm{C}\right)$, so that no ampli-

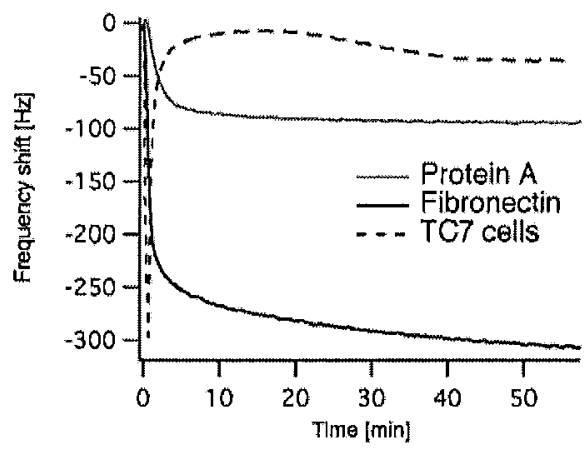

Fig. 6 The frequency decreases during adsorption of proteins or cells

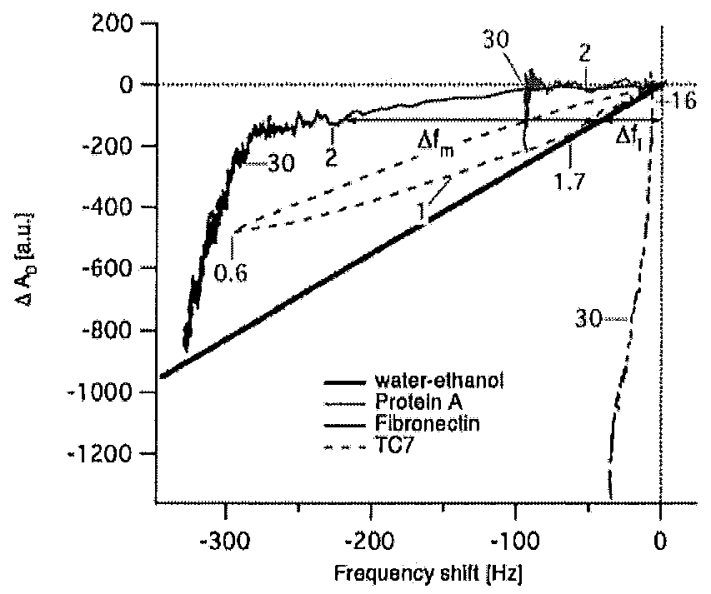

Fig. 7 Amplitude vs frequency-shift for adsorption by water-ethanol mixtures, protein, and cells. Reference time points (min) are given for each curve tude or frequency decrease can be attributed to changes in liquid properties. The curve remains above the waterethanol curve, and the adsorption can be globally fitted with two slopes. During the first $4 \mathrm{~min}$ the amplitude remains constant and the frequency decreases. These first minutes of protein $A$ adsorption corresponds to pure mass adsorption, where no energy losses occur (similarly to the curve B in Fig. 5). This phase corresponds to the formation of the first protein A layer [43]. Afterwards the amplitude begins to decrease and the frequency remains almost constant. The formation of the second monolayer occurs more slowly and energy losses arise. Similar behavior has been observed during adsorption of different proteins $[43,44,45,46]$ and cells $[47,48,49,50,51$, $52,53]$. This phenomenon might be principally due to the height increase of the protein adlayer and/or due to the increase of the constant loss tangent $\alpha$. It has been shown that the first protein A monolayer is denatured and has a height of $1 \mathrm{~nm}$, in contrast to the second monolayer, which is $3 \mathrm{~nm}$ high [54]. Therefore the decrease in amplitude during the formation of the second monolayer might be due to the increase in the height of the adlayer. Nevertheless, changes of $\alpha$ must also occur, because the conformation of proteins is different in the first and second layers, as is apparent from the less compact geometry in the second layer. Moreover the presence of water molecules entrapped inside the protein layer influences the mechanical properties of the adlayer. By rinsing the surface with deionized water, the second layer is washed out [43] and the frequency increases and reaches the end point of the first slope. During this process the amplitude shows a further small decrease of 128 a.u., which corresponds to additional energy losses due to the rinsing of some proteins.

The adsorption of a viscoelastic protein has been measured with fibronectin (Fig. 7). Rheological measurements have demonstrated that fibronectin solutions are very viscoelastic by presenting dependencies of $G^{\prime}$ and $G^{\prime \prime}$ with application of different shear stress (data not shown). We found that the large decrease in frequency happens simultaneously with a decrease in amplitude. In contrast to protein $\mathrm{A}$, the amplitude begins to decrease almost immediately after introduction of the solution, showing that the changes of solution properties towards water contributes to the decrease of $f$ and $A_{0}$. If the adsorbed fibronectin induced no energy losses, the real frequency shift due to adsorbed mass would be $\Delta f_{\mathrm{m}}$ and $\Delta f_{l}$ would correspond to the contribution of changes in liquid properties. However, the liquid density and viscosity are constantly modified due to protein adsorption, so it is difficult to determine in time the precise influence of liquid properties, adlayer properties and mass adsorption on the frequency shift. But similarly to protein $\mathrm{A}$, the amplitude vs frequency shift curve can be fitted by at least two different lines. After $22 \mathrm{~min}$, $A_{0}$ decreases drastically in comparison to $\Delta f$. We can estimate that at that stage the contribution of the liquid remains rather constant, because most of the protein adsorption has already occurred. The amplitude decrease corresponds to an increase of $\alpha$ and/or of the thickness of the 

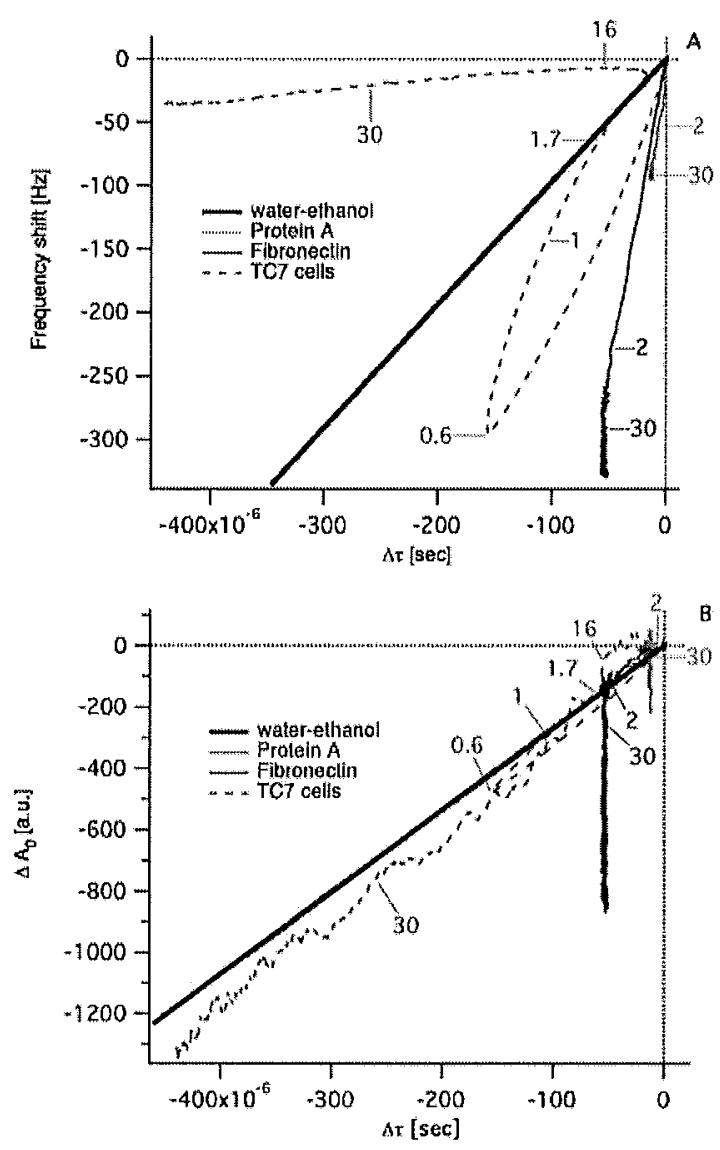

Fig. 8 A Frequency shift vs the decay time constant shift for liquid mixtures, proteins, and cells. B. Amplitude vs the decay time constant shift for the same adsorptions. Cell behavior differs from protein adsorption. Reference time points (min) are given for each curve

protein adlayer. The study of adlayer state after rinsing of the surface with water is described elsewhere [43].

Finally, we studied the adsorption of the TC7 cells (Fig. 7). Before introduction of the cell solution the QCM was stabilized with cell culture medium, so that the electrode surface contains already adsorbed proteins and ions. With introduction of the TC7 cells, the frequency drastically decreases during $40 \mathrm{~s}(\Delta f=-380 \mathrm{~Hz})$ and thereafter increases during $16 \mathrm{~min}$ to reach the initial frequency. $A_{0}$ shows similar behavior. The slopes of the decrease and increase of $\Delta f$ and $\Delta A_{0}$ during the first $16 \mathrm{~min}$ are almost similar, meaning that a same process of adsorption-desorption occurs. Afterwards the frequency decreases less than $50 \mathrm{~Hz}$ in $40 \mathrm{~min}$, in contrast to $A_{0}$, which shows a strong decrease in time. We have observed that a suspension of non-adsorbing hematopoietic THP1 cells induces no frequency shift and an insignificant decrease of amplitude. Therefore the frequency and amplitude changes are most likely due to adsorbing cells. At present little is known about the precise temporal and molecular changes occurring at the interface between cells and the electrode surface during cell adsorption. We can assume that the shape of the cell gradually changes during adsorption, expand- ing laterally and reducing the total cell height. During this process, focal points of contact with the substratum are developed and these sites of cell adhesion crucially control cell shape and migration [55]. This suggests that the non-slip condition may not be valid. Formation of focal contact points also reshapes the cytoskeleton and this process changes the mechanical properties of the cytoplasm. It is likely that the mechanical properties of the cytoplasm affect the $A_{0}$ decrease.

All these processes participate to the measured energy losses and it can be helpful to consider $\Delta A_{0}$ and $\Delta f$ versus the shift in decay time constant $\tau$ (Figs. 8A and $8 \mathrm{~B}$ ), which represents the ratio of adsorbed mass over the energy losses. Under water loading $\tau$ is approximately $3000 \times 10^{-6} \mathrm{~s}$. It can be seen that the behavior of proteins and cells differs considerably. For protein $\mathrm{A}$ and fibronectin, $\Delta \tau, \Delta f$, and $\Delta A_{0}$ decrease constantly during the first $2-3 \mathrm{~min}$. Afterwards $\tau$ remains constant and the amplitude and frequency continue to decrease. In contrast, $\tau$ is constantly modified during cell adsorption. Similarly to $f$ and $A_{0}$, it decreases during the first $40 \mathrm{~s}$ and increases thereafter during $16 \mathrm{~min}$ to reach the initial value and decreases afterwards. Interestingly all $A_{0}$ vs $\tau$ values move along a specific slope, which lies just under the water-ethanol line (Fig. 8B).

It seems that $\tau$ decreases as long as changes in density and/or viscosity of liquid/mass occur directly on the electrode surface. After full coverage of the quartz surface with the new adlayer mass (for proteins) or the new liquid (for mixtures), a second slope appears in the $A_{0}$ vs $\tau$ curve. For protein A $\tau$ decreases during formation of the first monolayer and remains constant during formation of the second monolayer. In the second phase the amplitude decreases continuously at a constant decay time constant, i.e. at a constant mass/energy loss ratio. Therefore the kinetic energy due to the oscillation of the adsorbed mass $\left(L_{1}\right)$ has to increase since the energy losses increase. During the formation of the second layer, the mechanical properties of the adlayer are therefore conserved. Fibronectin shows different behavior during the first few minutes of adsorption. $A_{0}$ vs $\tau$ follows the water-ethanol curve due to changes of the density and viscosity of the protein solution in comparison with water. Simultaneously, fibronectin adsorbs and covers the whole electrode surface. Similarly to protein $\mathrm{A}$, the second adsorption phase occurs with a constant $\tau$, so that the adsorbed mass increases and dissipates energy losses proportionally to $\Delta m$. The stiffness of the new adlayer is therefore conserved during adsorption. For cell adsorption $\tau, f$, and $A_{0}$ decrease during the first few minutes, probably due to the solution exchange, where many cells enter in contact with the surface. Afterwards suspension equilibrates and all parameters increase to reach initial values. This phenomenon occurs more slowly than with proteins, because cells are larger and diffusion therefore takes longer. After $16 \mathrm{~min}$ cell adsorption leads to an increase of surface coverage, so that $\tau$ and $A_{0}$ decrease again. Optical measurements have shown that the surface coverage with cells is not complete after $40 \mathrm{~min}$, where $\Delta f=-35 \mathrm{~Hz}, A_{0}=-1330$ a.u. and 
$\tau=-440 \times 10^{-6} \mathrm{~s}$. The slope of the $A_{0}$ vs $\tau$ curve follows the water-ethanol curve, so that the viscosity-density product of the cells in expansion has to increase and is the main effect. It has to be mentioned that the QCM is only sensitive to $180 \mathrm{~nm}$ over the surface when water is in contact with the electrode, because the generated waves decrease exponentially into the liquid and the penetration depth depends on the density and viscosity of the liquid [9]. Therefore an increase of adsorbed mass can be detected during cell expansion, although the number of adsorbing cells remains constant. Similarly the total density just over the electrode surface can increase during cell adsorption. Nevertheless, the cell density is similar to water and the frequency shifts measured are smaller than for protein $A$ adsorption, so that the density is not much larger than the water density. $A_{0}$ and $\tau$ are nevertheless much larger than for protein $A$ and follow the water-ethanol curve, so that an increase of the cell viscosity has to occur. This result is not so surprising, because it is known that the cytoskeleton is reshaped during cell adsorption, and the cell becomes stiffer. Moreover the increase in cell viscosity can influence the quartz sensitivity, which would explain the small decrease of frequency after $16 \mathrm{~min}$ of adsorption. Therefore adsorption of cells induces changes of density and viscosity at the electrode surface and thus also affects the frequency.

\section{Conclusion}

The QCM is a powerful means of following the adsorption kinetics of different entities, from molecules to living cells. Nevertheless, different physical properties such as the liquid and mass viscosity can influence the measured frequency shift. Measuring additional parameters besides the frequency, $f$, is essential to distinguish between the contribution of the liquid and mass, and between mass adsorption and modification of viscoelastic properties. Here we present the information that is contained in the maximal oscillation and in the decay time constant in the transient technique. The maximal oscillation, $A_{0}$, is proportional to the vibration amplitude of the quartz crystal and it represents changes of resistance to motion. The decay time constant, $\tau$, represents the ratio of the kinetic energy of the adsorbed mass over its energy losses. It allows us to determine, first, if surface coverage is complete and, second, how the stiffness of the adlayer is changing with time. The interpretation of the QCM measurements is therefore enhanced by measuring $f, A_{0}$, and $\tau$, but additional experiments and modeling will be necessary to quantify each physical property separately.

Acknowledgments We gratefully acknowledge Laurent Spicher and Francis Bourqui for helping to build the QCM, Dr Silvio Hemmi for providing THP1 cells and Bianca Saam for help with cell culture. This work was supported by the Dr h.c. Robert Mathys Stiftung (RMS) Foundation and the Swiss National Scince Foundation (TopNano21).

\section{References}

1. Janshoff A, Galla H-J, Steinem C (2000) Angew Chem Int Ed 39:4004-4032

2. Salt D (1987) Handbook of quartz crystal devices. Van Nostrand Reinhold

3. Jones JL, Meiure JP (1969) Anal Chem 41:484

4. Meiure JP, Jones JL (1969) Talanta 16:149-150

5. Sauerbrey G (1959) Z Phys 155:206-222

6. Nomura T, Iijima M (1981) Anal Chim Acta 131:97-102

7. Saenger W (1987) In: Engelman DM, Cantor RC, Pollard TD (eds) Annual review of biophysics and biophysical chemistry. Annual reviews, Palo Alto, CA

8. Kankare J (2002) Langmuir 18:7092-7094

9. Kanazawa KK, Gordon JG (1985) Anal Chem 57:1770-1771

10. Rodahl M, Kasemo B (1996) Rev Sci Instrum 67:3238-3241

11. Nakamoto T, Kobayashi T (1994) IEEE Trans UItrason, Ferroelect, Freq Contr 41:806-811

12. Voinova MV, Jonson M, Kasemo B (2002) Biosens Bioelectron $17: 835-841$

13. Lee S-W, Himsberg WD (2002) Anal Chem 74:125-131

14. Hillman AR, Jackson A (2001) Anal Chem 73:540-549

15. Lucklum R, Behling C, Hauptmann P (1999) Anal Chem 71: 2488-2496

16. Marx KA, Zhou T, Sarma R (1999) Biotechnol Prog 15:522528

17. Muramatsu H, Egawa A, Ataka T (1995) J Electroanal Chem 388:89-92

18. Muramatsu H, Kimura K (1992) Anal Chem 64:2502-2507

19. Brookhaven Database of Proteins

20. Langone JJ (1982) Adv Immunol 32:157-252

21. Engel J, Odermatt E, Engel A, Madri JA, Furthmayr H, Rohde H, Timpl R (1981) J Mol Biol 150:97-120

22. Alexander S, Colonna G, Edelhoch H (1979) J Biol Chem 254: $1501-1505$

23. Suomalainen M, Nakano MY, Keller S, Boucke K, Stidwill RP, Greber UF (1999) J Cell Biol 144:657-672

24. Ebbinghaus C, AI-Jaibaji A, Operschal1 E, Schöffel A, Peter I, Greber UF, Hemmi S (2001) J Virol 75:480-489

25. Matthys RJ (1983) Crystal oscillator circuits. Wiley, New York, pp 69-77

26. Rodahl M, Höök F, Kasemo B (1996) Anal Chem 68:22192227

27. Buttry DA, Ward MD (1992) Chem Rev 92:1355-1379

28. Yang M, Thompson M (1993) Anal Chem 65:1158-1168

29. Kanazawa KK (1997) Faraday Discuss 107:77-90

30. Arnau A, Sogorb T, Jiménez Y (2002) Rev Sci Instrum 73: 2724-2737

31. Chagnard C, Gilbert P, Watkins AN, T Beeler, Paul DW (1996) Sens Actuators B 32:129--136

32. Auge J, Hauptmann P, Hartmann J, Rösler S, Lucklum R (1995) Sens Actuators B 24/25:43-48

33. Zhang C, Feng G (1996) IEEE Trans UItrason, Ferroelect Freq Control 43:942-947

34. Borovsky B, Mason BL, Krim J (2000) J Appl Phys 88:40174021

35. Martin SJ, Granstaff VE, Frye GL (1991) Anal Chem 63: 2272-2281

36. Muramatsu H, Dicks JM, Tamiya E, Karube I (1987) Anal Chem 59:2760-2763

37. Geelhood SJ, Frank CW, Kanazawa K (2002) J Electrochem Soc 149:H33-H38

38. Noël MAM, Topart PA (1994) Anal Chem 66:484-491

39. Martin SJ, Bandey HL, Cernosek RW, Hillman AR, Brown MJ (2000) Anal Chem 72:141-149

40. Bandey HL, Martin SJ, Cernosek RW (1999) Anal Chem $71: 2205-2214$

41. Voinova MV, Rodahl M, Jonson M, Kasemo B (1999) Phys Scripta 59:391-396

42. Schneider TW, Martin SJ (1995) Anal Chem 67:3324-3335 
43. Galli Marxer C, Collaud Coen M, Schlapbach L (2003) J Colloid Interface Sci 261:291-298

44. Shen D, Huang M, Chow L-M, Yang M (2001) Sensors Actuators B 77:664-670

45. Höök F, Rodahl M, Kasemo B, Brzezinski P (1998) Proc Natl Acad Sci 95:12271-12276

46. Höök F, Rodahl M, Brzezinski P, Kasemo B (1998) Langmuir $14: 729-734$

47. Galli Marxer C, Collaud Coen M, Greber T, Greber UF, Schlapbach L, Anal Bioanal Chem (in press)

48. Marx KA, Zhou T, Montrone A, Schulze H, Braunhut SJ (2001) Biosens Bioelectron 16:773-782

49. Zhou T, Marx KA, Warren M, Schulze H, Braunhut SJ (2000) Biotechnol Prog 16:268-277
50. Wegener J, Seebach J, Janshoff A, Galla H-J (2000) Biophys J 78:2821-2833

51. Otto K, Elwing H, Hermansson M (1999) J Bacteriol 181: $5210-5218$

52. Fredriksson C, Khilman S, Kasemo B (1998) J Mater Sci Mater Med 9:785-788

53. Janshoff A, Wegener J, Sieber M, Galla H-J (1996) Eur Biophys J 25:93-103

54. Collaud Coen M, Lehmann R, Gröning P, Bielmann M, Galli C, Schlapbach L (2001) J Colloid Interface Sci 233:180-189

55. Aplin AE, Howe A, Alahari SK, Juliano RL (1998) Pharmacol Rev 50:197-264 